\title{
DIGITAL ENERGY SIMULATION OF BUILDINGS PROTECTED BY MUNICIPAL HERITAGE POLICIES IN THE FRAMEWORK OF ENERGY RENOVATION PROJECTS
}

\author{
B. Serrano Lanzarote ${ }^{1,}$ *, P. Carnero Melero ${ }^{2}$, V. Valero Escribano ${ }^{2}$, L. Ramírez Pareja ${ }^{2}$ \\ ${ }^{1}$ Universitat Politècnica de València - apserlan@mes.upv.es \\ ${ }^{2}$ Instituto Valenciano de la Edificación - (pcarnero, vvalero, lramirez) @ five.es
}

Commission II - WG II/8

KEY WORDS: Energy simulation, Heritage, School, Renovation

\begin{abstract}
:
The energy simulation is a key tool when designing renovation actions on buildings. In the framework of the InterregMed SHERPA project, bound to trigger and manage energy renovations in public buildings, the digital analysis of an educational building affected by the municipal heritage protection has been carried out. The building is the CIPFP Blasco Ibáñez, catalogued as a monument of local interest in Valencia (Spain) city planning, where the heritage value of its facades (main and interior), roof and internal spatial structure is identified. The methodology used consists in performing an energy audit of the building in order to be able to customize a digital energy model. By means of an hourly dynamic energy simulation tool, the current status of the building and its systems can be determined, and energy renovation actions can be outlined. The use of digital analysis tools is of utmost interest in buildings declared as municipal heritage sites since enables the study to be performed in a non-intrusive manner. Several points of energy improvement are identified. There are some actions that can be performed without affecting parameters protected by the heritage status, and some others which need to be modified in order to be compliant with it. Furthermore, the digital analysis through energy simulation tools also allows to perform detailed calculations about the energy, environmental and economic savings associated with the measures. The assessment has proved the need to promote research and testing of new solutions and technologies to improve the energy efficiency of heritage buildings.
\end{abstract}

\section{INTRODUCTION}

\subsection{State of the Art}

Until recently, heritage was exempt from the energy discussion, because improving the energy efficiency of historic buildings usually meant alterations, which impact upon their integrity and historical value. The general exemption of historic buildings from energy regulations is increasingly questioned, including by conservation interests. (J Owen Lewis, 2013)

For years, many impact European forums (such as the European Construction Technology Platform -ECTP-, its Energy Efficient Buildings Committee -E2B- and JPI Cultural Heritage and Global Change) have expressed the need of energy retrofitting of heritage buildings and the importance to legislate it because of its significance.

In the case of Spain, despite the National Energy Plan 20142020 recognizing the need for specific programs to improve the energy efficiency of protected buildings, the last update in 2019 of the 'Energy Saving Basic Document' (Documento Básico de Ahorro de Energía, DB-HE) of the "Technical Building Code" (Código Técnico de Edificación, CTE) makes no special mention of heritage buildings. These regulations, with new requirements to comply with Directive 2010/31/EU (EPBD), update the energy performance requirements for both new buildings and existing ones and exclude from compliance buildings with recognised heritage values. This limitation has long been identified, hence the Spanish participation in related European projects and the existence of groups and workshops on the subject. An example of it is the BEEP project (BIM for
Energy Efficiency in the Public sector), from the ENI CBC MED Programme (ENI CBC MED, 2019), which aims at strengthening the use of Building Information Modelling (BIM) to enhance energy efficiency in buildings. The testing of this emerging technology on built heritage will be performed to demonstrate its scalability to the entire building stock.

The urgency to design energy-heritage retrofitting solutions which balance heritage and energy values has also been identified. Currently there are already initiatives working in this line, like Historic England public body, which have addressed the problem of how to improve energy efficiency of historic buildings in ways that are sympathetic to their historic character. As an example they have published a guide 'Energy Efficiency and Historic Buildings: How to Improve Energy Efficiency' (Historic England, 2018) to address energy renovation of historical buildings in a holistic way, trying to achieve a right balance between the energy renovation upgrade and the preservation of heritage values. Digital energy simulation of heritage buildings should be the first step in this path, since it is a fact that it is a key tool when designing renovation actions in the different building typologies (Aste et al., 2012).

Although there are no definitive data on numbers of buildings that have architectural or historical value, and numbers of buildings with heritage significance differ between countries and between continents (Örn, 2018). According to RIBuild project, historic buildings make up $30 \%$ of the European building stock, they account for more than a third of the total energy consumption of buildings in the EU and their potential for energy savings is about $15-20 \%$.

\footnotetext{
* Corresponding author
} 


\subsection{Building Presentation}

The building complex considered is the CIPFP Blasco Ibáñez an in-use educational building, built in 1940 in the city centre, and not refurbished ever since. Therefore, the energy features of the building, specially the envelope is not updated to energy standards, and causes high inefficiencies, important energy consumption and comfort problems. It is considered a heritage monument by Valencia city planning.

The building complex, whose architectural style responds to the so-called historicist, eclectic style or revival, is composed by 3 blocks, with 3, 4, and 5-storey buildings, respectively. It has a total surface area of $11,900 \mathrm{~m}^{2}$.

The complex, devoted exclusively to educational purposes, includes classrooms, offices and other educational facilities. There are 1,545 users in total, of which 1,400 are students.

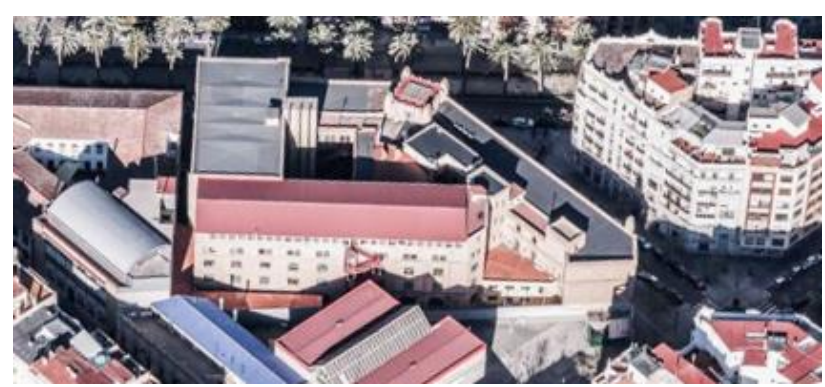

Figure 1. Aerial view of the building complex.

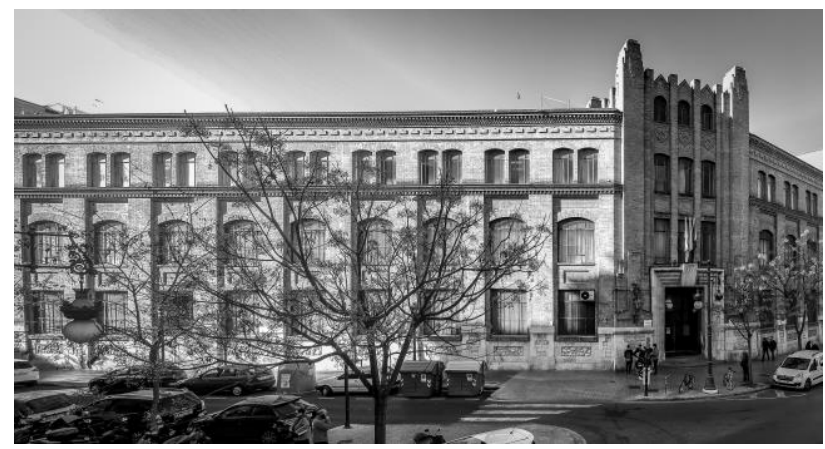

Figure 2. Façade of CIPFP Blasco Ibáñez.

The building is located in the expansion district of Valencia regulated by the 'Special Plan for the Protection of the Ruzafa Sur - Gran Vía' (Plan Especial de Protección del Ensanche de Valencia, PEP 2). In the Catalogue of this Special Plan, it is considered as a 'Property of Local Relevance' (Bien de Relevancia Local, BRL) with 'Monumental Protection'. According to this plan, the level of monumental protection is attributed to those buildings which, in addition to having environmental value and exceptional character as monuments -with the consequent generalised, institutional and legal recognition-, have architectural and historical values corresponding to the maximum level of protection.

The type of works eligible for this protection degree basically correspond to conservation and restoration works.

Regarding the energy-related state of the building, it is very intensive in terms of electricity and natural gas consumption.

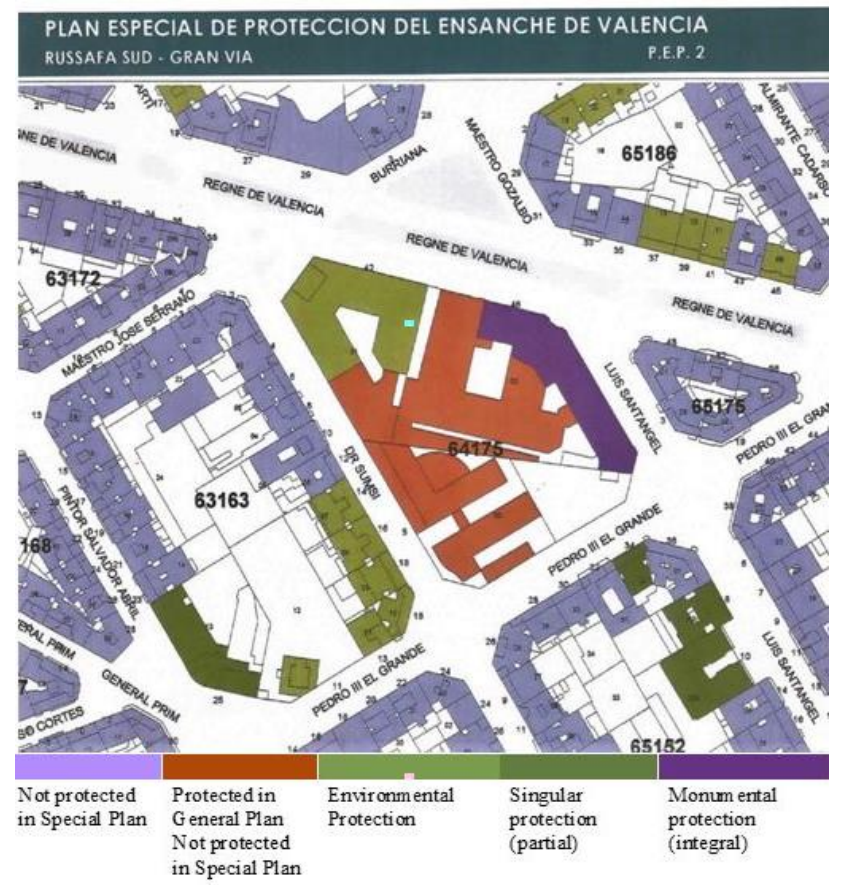

Figure 3. Protection level of the building complex.
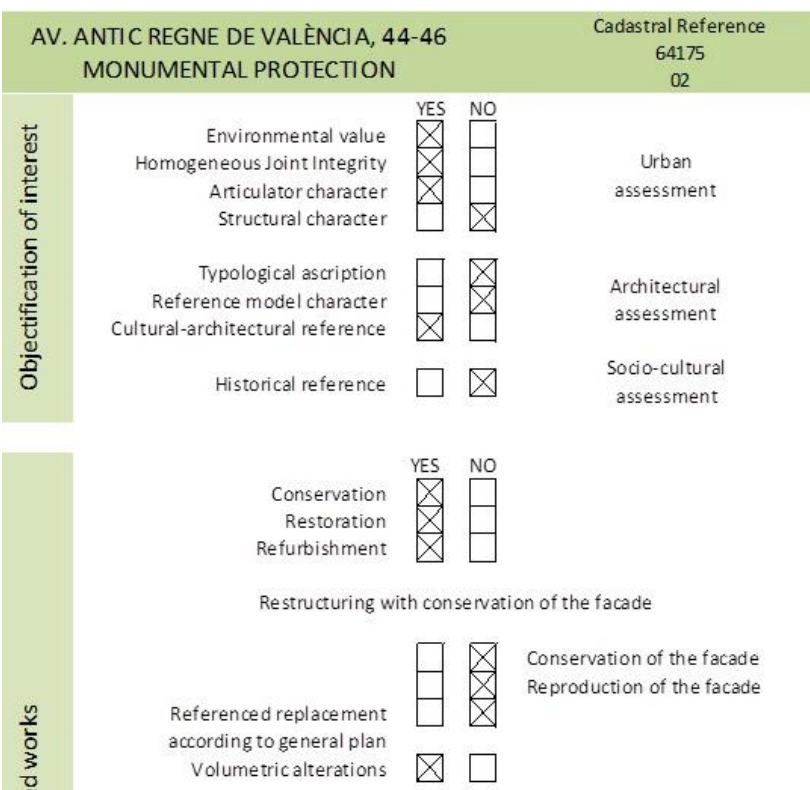

In the volumetric alterations sheet, the conditions and parameters of the permitted modifications are defined.

The urban planning regime of the buildings with referenced substitution according to the General Plan is defined in the corresponding alignment plan. In the annex "Additional documentation on the roofs of the protected buildings" is contained the normative documentation regarding the roof of the building.

It is included in the catalog as a Local Relevance Asset

Figure 4. Applicable regulations according to PEP 2. 


\subsection{Link with Sherpa Project}

The CIPFP Blasco Ibáñez was a pilot case of SHERPA project (Interreg MED SHERPA project, 2019)., during the regional testing phase of the project. SHERPA, as a Testing and Capitalizing EU project financed by the Interreg Med Programme, aimed to accelerate the implementation of EU Directives on Energy Performance in Buildings (2010/31/EU) and Energy Efficiency (2012/27/UE) among other EU directives and connected policies, and aims to reach the $20 \%$ energy efficiency EU target by 2020 .

A mottled consortium of Mediterranean countries participated in the different phases of the project. The methodology was developed and tested based on the energy analysis performed in 100 regional pilot buildings and later transfered and capitalised in a wide variety of municipal buildings. All of this by means of different accessory tools, such as information system applications, training material, communication and sharedknowledge-and-experiences platforms, and digital energy simulation tools among others.

\subsection{Energy Simulation of Historical Buildings}

Having a detailed and thorough baseline for the energy improvement of historical buildings is a challenge. Most of the time, the age of the building and the degree of protection does not allow to obtain actual data of the main constructive features of the construction. Also, hardly ever the original construction plans of the building exist or, if they do, doe not include the needed information. Furthermore, in patrimonial buildings the physical interventions in the building in order to perform energy-related measurements are seldom feasible.

However, energy simulation brings about a possibility to perform a diagnosis which can serve to obtain information about the current state of the building, and to propose improvement measures. A digital model can be built from estimations according to the features of the constructive elements, questionnaires to the people using the building, and geometric and systems' information gathered by means of a direct inspection. Then, this virtual model can be calibrated and fine-tuned with the information of the energy bills provided by the utility. Depending on the available information, the digital energy simulation can have different degrees of accuracy. Nevertheless, in the case the energy model does not precisely represent the current state of a building, very often it can provide valuable information regarding the improvements associated with certain energy efficiency measures. This is due to the fact that minor discrepancies balance out between the socalled current state of the building, and the theoretical improved one.

Having a virtual model also has additional benefits when dealing with protected heritage buildings. It is mainly because when the time comes to perform any intervention in the building, whether is structure, health, aesthetic or energy related, it is capital to make the most of it. By means of digital energy simulation tools it is possible to couple the effect of several possible actions, and get a knowledge of their collective effect, hence maximizing the benefit of a single intervention.

This holistic approach is undoubtedly very beneficial when dealing with historical buildings, because a certain desired effect can be reached with different kinds of measures. For instance, if there is a problem of excessive indoor temperature, several renovation scenarios can be considered, and then they can be balanced with the abiding of the heritage protection of the building. Using digital energy models could reveal that changing the indoor cooling units for more efficient models would yield similar results as installing an ETICS, this latter option with obvious incongruity with the patrimonial protection of the façade, for instance.

Furthermore, having a virtual digital simulation model of a historical building could also serve as a day-to-day management tool, as well as a prediction of the behaviour of the building under a new environmental situation.

\section{METHODOLOGY AND RESULTS}

\subsection{Methodology}

The following methodology was followed as part of SHERPA's testing phase, in which a detailed energy analysis was required in order to try to extrapolate results that later will be capitalised.

A digital twin of the building was developed by means of an extensive energy audit (ISO 50001, 2011), which comprised the collection of energy bills, and a detailed diagnosis of the building and its systems.. Using this energy model, the performance of different aspects of the three building units composing the CIPFP Blasco Ibañez was assessed. The use of digital energy simulation tools is key, and of utmost interest in the case of heritage buildings, since it allows to perform diagnosis and improvement calculations in a non-intrusive manner.

The software used to create the energy model, Herramienta Unificada LIDER CALENER (Código Técnico de la Edificación, 2017), is based on the calculation engine DOE2.

After the analysis, the gathered information was introduced in the Information System Application created specifically for the SHERPA project by the International Centre for Numerical Methods in Engineering (CIMNE). The tool enables to manage the great amount of data that the public building stock involves. Moreover, when certain actions are performed on a particular building, it eases the management of such information and the recording of the evolution. It facilitates, for instance, keeping track of different Energy Efficiency Measures (EEM) applied, as well as testing its actual effect by means of the impact in the delivered energy by the utility.

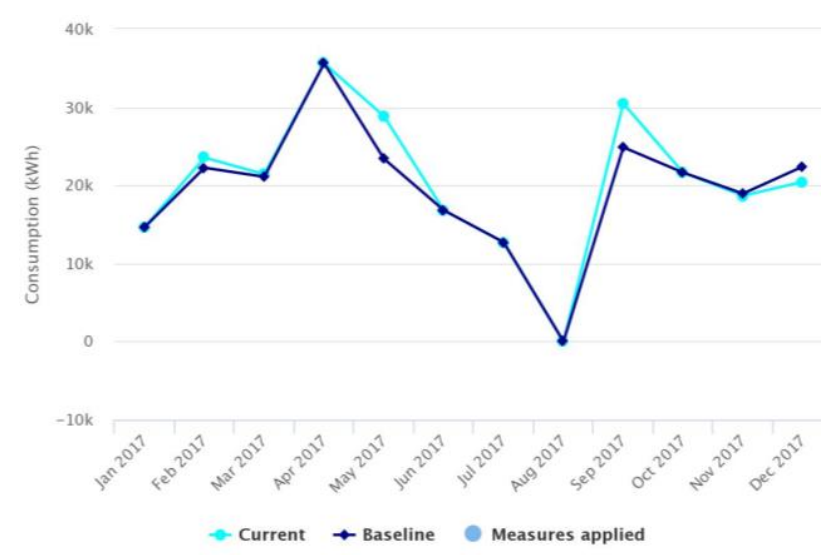

Figure 5. Information System Application of the electricity consumption of CIPFP Blasco Ibáñez. 
The system enables those public bodies responsible for managing large public building stock to potentiate its capabilities to support decision-making and strategic planning for building renovation. Moreover, it is very useful in order to perform a benchmark in terms of energy consumption of several buildings. In the case of CIPFP Blasco Ibáñez, it was possible to compare its energy performance with 198 other educational buildings.

Other tools developed by SHERPA are the Building Identification Factsheet, which helps synthesizing the information in a single format, very convenient when dealing with a wide variety of buildings. This is specially the case of the patrimonial buildings, very common in the public stock. Afterwards, with all gathered information in the diagnosis, and making use of the different virtually tested energy efficiency measures, along with the corresponding financial assessment, the energy renovation project could be drafted.

\subsection{Results}

The results of SHERPA's testing phase on CIPFP Blasco Ibáñez, as for every other regional pilot case, was the Energy Renovation Building report. This document gathered all the collected information of the diagnosis, but most importantly it included a series of Key Performance Indicators (KPIs), identification and evaluation of the energy saving measures assessed.

The current state of the building is responsible for the emission of $115,10 \mathrm{tCO}_{2}$ each year.

\begin{tabular}{|c|c|c|c|}
\hline $\begin{array}{r}\mathrm{CO} 2 \\
\text { Emissions }\end{array}$ & Electric energy & 74,14 & tn $\mathrm{CO}_{2} / \mathrm{y}$ \\
\hline & Thermal energy & 40,95 & tn $\mathrm{CO}_{2} / \mathrm{y}$ \\
\hline & Total Energy & 115,10 & tn $\mathrm{CO}_{2} / \mathrm{y}$ \\
\hline & Global Surface & 8,99 & $\mathrm{~kg} \mathrm{CO}_{2} / \mathrm{m} 2 \cdot \mathrm{y}$ \\
\hline \multirow[t]{3}{*}{$\begin{array}{r}\text { Global } \\
\text { Surface } \\
\end{array}$} & Electric energy & 17,50 & $\mathrm{kWh} \cdot \mathrm{e} / \mathrm{m}^{2} \cdot \mathrm{y}$ \\
\hline & Thermal energy & 12,70 & $\mathrm{kWh} \cdot \mathrm{th} / \mathrm{m}^{2} \cdot \mathrm{y}$ \\
\hline & Total Energy & 30,20 & $\mathrm{kWh} / \mathrm{m}^{2} \cdot \mathrm{y}$ \\
\hline \multirow[t]{3}{*}{ Users } & Electric energy & 160,00 & $\mathrm{kWh} \cdot \mathrm{e} / \mathrm{u} \cdot \mathrm{y}$ \\
\hline & Thermal energy & 116,08 & $\mathrm{kWh} \cdot \mathrm{th} / \mathrm{u} \cdot \mathrm{y}$ \\
\hline & Total Energy & 276,08 & $\mathrm{kWh} / \mathrm{u} \cdot \mathrm{y}$ \\
\hline \multirow[t]{3}{*}{$\begin{array}{r}\text { Operating } \\
\text { hours }\end{array}$} & Electric energy & 83,30 & $\mathrm{kWh} \cdot \mathrm{e} / \mathrm{h}$ \\
\hline & Thermal energy & 60,43 & $\mathrm{kWh} \cdot \mathrm{th} / \mathrm{h}$ \\
\hline & Total Energy & 143,74 & $\mathrm{kWh} / \mathrm{h}$ \\
\hline
\end{tabular}

Table 1. Main KPIs for CIPFP Blasco Ibáñez .

Moreover, since the maintenance is focused mainly on the aesthetic aspect of the building, the energy facilities are often neglected. It was the case of the heat generators, which not only were old, but also presented several deficiencies in terms of insulation and operation.
The outdated elements of the lighting installation stand for great potential for energy renovation given the great size of the installation, and its intensive use in terms of occupation. Many lights identified are fluorescent, with malfunctioning present causing not only high energy consumption, but also visual discomfort.

In the case of CIPFP Blasco Ibáñez, mainly due to its patrimonial and protection status, the actions were focused on elements which interfered the least with the façade, roof and internal space structure, focusing on the actions could be considered regarding the management and performance of service installations and indoor systems. Even more if it is considered the importance revealed by the digital energy analysis, where $46 \%$ and over $43 \%$ of the total energy was due to the indoor lighting installation, and HVAC systems respectively.

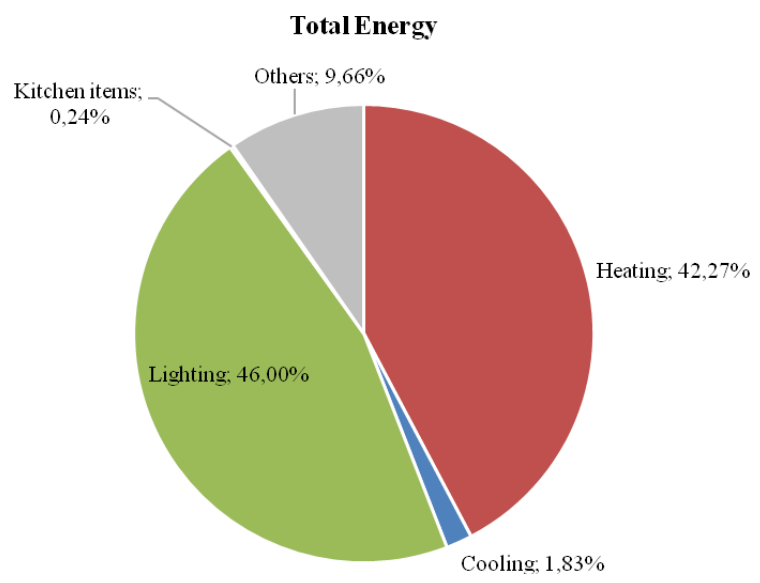

Figure 6. Before-renovation energy consumption of CIPFP Blasco Ibáñez.

The energy analysis, however, considered also a set of different passive and active measures which provided theoretical energy saving scenarios. A total of 11 EEMs were studied, 2 passive and 9 active ones, by means of the digital energy simulation model energy and economic parameters were obtained.

The results' summary was the following:

\begin{tabular}{|l|c|c|c|}
\hline EEM & \multicolumn{3}{|c|}{ Results } \\
\hline Window renovation & $\begin{array}{c}\text { Investment } \\
(\boldsymbol{(})\end{array}$ & $\begin{array}{c}\text { Energy } \\
\text { Savings } \\
(\boldsymbol{\%})\end{array}$ & $\begin{array}{c}\text { ROI } \\
(\mathbf{y r})\end{array}$ \\
Envelope renovation & $12,480.96$ & 2.52 & 18.62 \\
HVAC efficiency & $5,200.00$ & 4.60 & 3.17 \\
VRF technology & $199,993.00$ & 30.22 & 25.26 \\
Boiler change & $31,533.92$ & 5.81 & 21.41 \\
LED technology & $98,821.96$ & 31.04 & 6.96 \\
Presence detectors & $2,100.00$ & 0.88 & 5.26 \\
Natural light profit. & $7,408.70$ & 20.38 & 0.82 \\
Control and & $5,000.00$ & 8.91 & 1.60 \\
Monitoring & $34,303.50$ & 3.21 & 21.69 \\
Other equipment & 629.00 & 0.50 & 2.81 \\
Stand-by removal &
\end{tabular}

Table 2. Summary results of EEM in CIPFP Blasco Ibáñez. 
It can be seen that the passive measures, commonly conceived as the ones with the greatest energy saving impacts, do not show such features for the case of CIPFP Blasco Ibáñez. Moreover, regarding the active measures, which tend to be more inexpensive and more profitable, have different outcomes depending on the service they affect; HVAC, lighting, or general equipment.

\subsection{Discussion}

Different criteria could be adopted in order the develop the energy renovation project of any building. Nevertheless, the special patrimonial characteristics of the building should have a leading role in the drafting of energy efficiency actions. This is due to the fact that it hinders even more carrying out some of the measures or favours some technologies over others with higher impact on the protected areas of the building.

The window renovation measure, for instance, would need to consider the extra cost of a window that meets heritage regulation requirements, in terms of materials and design, in relation to a standard window.. Also, acting on the thermal energy generation systems may also be affected by the municipal regulation, performing certain actions could force to abide by the national efficiency regulation (Ministerio de Industria, Energía y Turismo, 2013), more strict than in the time the building was first constructed. This could be the case of the evacuation of the exhaust gases in boilers and the restrictions on the layout of the chimney, for instance. Similar arguments could be risen on the topic of the location of outdoor units in the framework of air-conditioned devices, such as VRF technology systems.

Regarding the fully interior interventions, the energy efficiency analysis becomes much closer to conventional buildings. It is the case of CIPFP Blasco Ibáñez, which does not have any restrictions regarding the indoor space, other than the distribution. Hence, the lighting technology replacement, or the installation of small, not-intrusive, control and management devices are to gain weight in the final balance.

The digital energy analysis proved that the actions addressed to the lighting installation; the LED technology, presence detectors and natural light profiting, have great impact and profitability, in terms of energy and economic savings. Thanks to the energy simulation, it could also be proved that the substitution of the lights for a more efficient technology had also the side effect of lowering the high energy consumption in cooling. This is due to the decrease in the internal loads of heat given off by the previous outdated lighting systems. Also, with detailed energy modelling, the increase in visual comfort may also be assessed, which would affect in productivity of the students and the staff.

\section{CONCLUSIONS}

\subsection{Energy Renovation of Historical Building}

Historical buildings are a challenge as far as energy renovation projects are concerned. On top of the common restrictions of conventional energy improvement interventions, such as the high investment or the inconvenience of the works, the issue of the strict regulation implies important constraints.
The main obstacle identified in the analysis of the heritage building CIPFP Blasco Ibáñez has been the fact that the energy analysis must be performed 'ad hoc'. Standardized procedures, simulations and results need to be checked and revised with deep knowledge of the regulatory framework which limits conventional interventions. This matter does not only stretch the times considered for every phase of the project, but also causes an increase in the prices of both the project and the execution of the energy renovation actions.

And while having digital energy simulation tools help to address the analysis in the holistic way these types of buildings call for, it is not enough to consider the patrimonial aspect as a whole. Moreover, the common difficulty to intervene in the envelope, the greatest element in the demand of energy, due to regulatory protection, is usually coupled with the absence of renewable generation systems abiding with such legislative framework.

Furthermore, since the patrimonial building sector is a minority of the building stock, integrated solutions for new technologies are still scarce. This is the case of the installation of renewable photovoltaic systems on the rooves, which due to regulatory restrictions have remained out of the scope of the analysis.

\subsection{Further development}

In order to increase the energy performance of historical buildings more innovation is needed in the field of the renewable generation systems. Elements which could be fully integrated with similar aesthetic values in the building, such as photovoltaic tiles (Baha, James, 1997), or photovoltaic glazings (Skandalos, 2015) could boost the energy performance of many historical buildings.

\section{ACKNOWLEDGEMENTS}

The authors of this paper want to acknowledge the consortium of the SHERPA project, as well as the Interreg Med Programme.

\section{REFERENCES}

Aste, N., Adhikari, R.S., Buzzetti, M., 2012. Milano, Italy. doi.org/10.3992/jgb.7.4.144.

Ayuntamiento de Valencia, 2006: Plan Especial de Protección del Ensanche de Valencia - Russafa Sud - Gran Vía P.E.P.2.

BEEP Project (BIM for Energy Efficiency in the Public Sector), ENI CBC MED, 2019. http://www.enicbcmed.eu/projects/beep (30 January 2020).

Campbell, M., Partridge, A., Soto, P., 2013. Cities of Tomorrow - Action Today. En: URBACT II Capitalisation. More Jobs: Better cities - A framework for a Better Action on Jobs, 2013. https://urbact.eu/sites/default/files/import/general_library/19765 _Urbact_WS2_MORE_JOBS_low_FINAL_01.pdf February 2017)

Código Técnico de la Edificación, 2017. Herramienta Unificada LIDER-CALENER (HULC) Software, Version 1.0.1564.1124. Official EPC Software. https://www.codigotecnico.org (22 October 2018). 
European Construction, built environment and energy efficient building Technology Platform (ECTP) - http://www.ectp.org

Historic England, 2018. Energy Efficiency and Historic Buildings.

https://historicengland.org.uk/images-books/publications/eehbhow-to-improve-energyefficiency/heag094-how-to-improveenergy-efficiency/

Joint Programming Initiative on Cultural Heritage (JPI Cultural Heritage). http://jpi-ch.eu/

Ministerio de Fomento, 2019: Código Técnico de la Edificación CTE.

Ministerio de Industria, Energía y Turismo, 2013: Reglamento de Instalaciones Térmicas en los Edificios.

Ministerio de Industria, Energía y Turismo, 2014: Plan Nacional de Acción de Eficiencia Energética 2014-2020.

Örn, T., 2018. Energy Efficiency in Heritage Buildings Conservation Approaches and Their Impact on Energy Efficiency Measures (Licentiate thesis). Luleå University of Technology

SHERPA., Interreg MED, 2019. https://sherpa.interreg-med.eu/ (30 January 2020). 